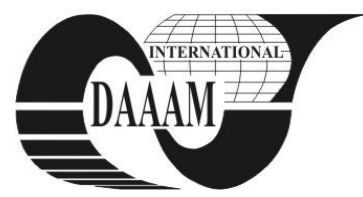

Annals of DAAAM for 2011 \& Proceedings of the 22nd International DAAAM Symposium, Volume 22, No. 1, ISSN 1726-9679 ISBN 978-3-901509-83-4, Editor B. Katalinic, Published by DAAAM International, Vienna, Austria, EU, 2011 Make Harmony between Technology and Nature, and Your Mind will Fly Free as a Bird

Annals \& Proceedings of DAAAM International 2011

\title{
RELATIONSHIP BETWEEN PROCESSES AND PROJECT MANAGEMENT
}

\author{
KOSTELAC, D[razen]; MATRLJAN, D[amir] \& DOBOVICEK, S[andro]
}

\begin{abstract}
Many organizations are not getting a good relationship between process and projects. Projects have a bad reputation - the odds of success are usually not good. What often happens when projects start to waver is that there are invisible forces that try to transform the project into a process. The odds of a successful transformation are not good unless the transformation itself is acknowledged as a process. In reviewing the definitions and literature, it becomes apparent that correst thinking is that all work is a process and that projects fit into the framework of process management. If you can not describe what you are doing as a process, you do not know what you are doing.

Key words: organization, processes, balanced scorecard, project portfolio management
\end{abstract}

\section{INTRODUCTION}

A business process is a sequence of tasks with clear boundaries which are performed by several organizations. A business is a social construct. The elements of business processes are tasks and decisions and their relationships. PMO processes are: Project management (PM), Program management, Project portfolio management (PPM). Still, lots of companies do not have all processes modeled, and therefore, they do not have standard plans developed for all of them. (Gareis \& Roland, 2005)

\section{BSC MODEL (BALANCED SCORECARD MODEL)}

The objective of the Balanced Scorecard model is not to create a new system for analyzing numbers, but to provide an integrated management approach from which balanced control units can be derived. A balance between monetary and nonmonetary, between short- and long-term and between internal and external factors should be developed. The Balanced Scorecard considers companies from the financial perspective, the customer perspective, the process perspective and the employee and/or potential perspective. (Gareis \& Roland, 2005)

\subsection{BSC perspectives}

The financial perspective deals with the economic and financial objectives of a company and considers various characteristics of profitability. Profitability ratios and income ratios are the focus of attention. The customer perspective considers factors such as customer loyalty, market share, customer satisfaction, cooperation with partners, etc.Even with strategic planning for project management,special problems can always occur. (Kerzner \& Harold, 2001)

In the process perspective only those processes are considered which have an influence on the achievement of the company's financial objectives or on customer satisfaction. The cost structure, delivery time or the manner of dealing with complaints in relation to these processes is considered.

The employee and/or potential perspective is of special importance because of its long-term effect on the company's success. The key to success of every company is investing in knowledge and using the abilities of each employee. Employee satisfaction, motivation and continuous education, and employee development are the main factors in this perspective.

\section{PROBLEM SITUATION}

Today, after 20 years on the market, JGL has transformed into an agile, project-oriented pharmaceutical company. According to independent estimates, the company holds about $5 \%$ share of the Croatian market and is third indigenous manufacturer in Croatia. The total revenue growth rate for the last eight years of about $30 \%$ per annul makes the company one of the fastest growing and one of the most stable in the country.

JGL have some other problems regarding relationship between process management and project management: limited resources (few process managers). So, the HR (Human Resource) problem and in-house expertise, as well as rather enthusiastic plans should be in better relationship.

Not describing all processes in JGL (sales, export activities, some productions processes). These processes are critical for our business, so the modeling process and standard plans development for them should start as soon as possible. Demand for describing the PMO processes with ARIS is described in the following picture (Figure 1) :

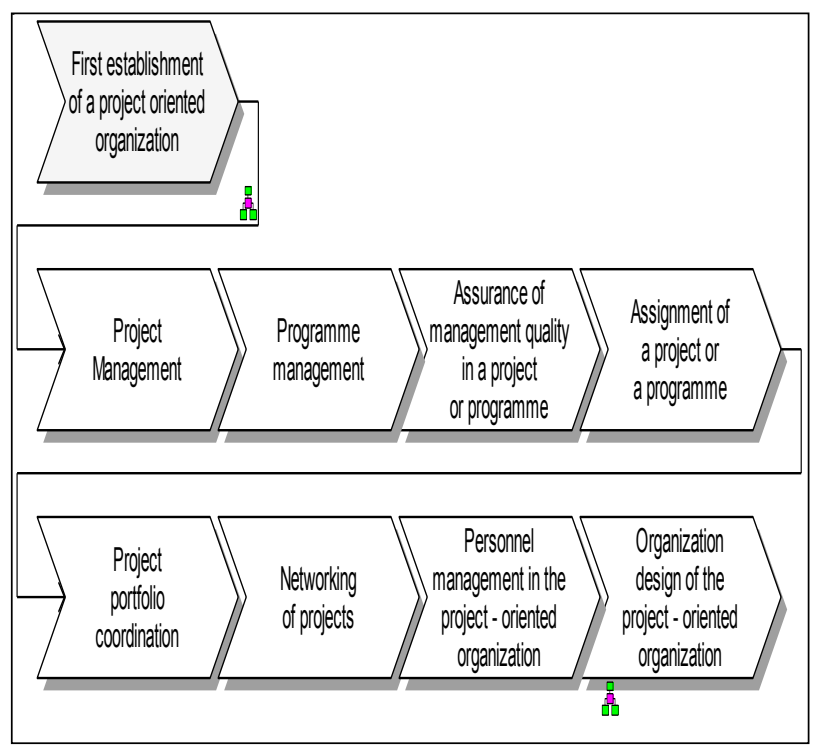

Fig. 1. Project management processes developed in ARIS (***, 2011) 


\section{PROPOSAL FOR PROBLEM SOLUTION}

\subsection{Model PMO process with ARIS and developing standard project plans}

Project management is a business process which is fulfilled in projects. The documentation of the project management process promotes communications about the objectives, tasks, responsibilities and results of project management process and its sub-process must be described. So, our goal is further modeling of processes and developing further standard plans. In project management the project objectives are: scope, schedule, resources, costs, earnings, risks, organization, culture and project context .The dimensions of the project context are the pre-project and post-project phases, relevant project environments, other projects, the company strategies and the business case for the investment which is initiated by a project.

\subsection{Objectives of the project management process:}

Developing the structural prerequisites for the realization of the project objectives are key performance indexes of each project. Efficient performance of the project start, project controlling, project close-down, and the continuous project coordination are very significant for project portfolio management.

The general objective of project portfolio management is the optimization of project portfolio results. Different objectives are pursued in the various business processes of project portfolio management. The central objectives of assigning a project or program are the selection of a favorable investment and the adequate organization form for initializing the investment. (Gareis \& Roland, 2005)

The objectives of the project portfolio coordination are the coordination of the objectives of the projects of the portfolio, the coordination of the internal and external resources used on these projects, the organization of learning from and between the projects, and the determination of the project priorities.
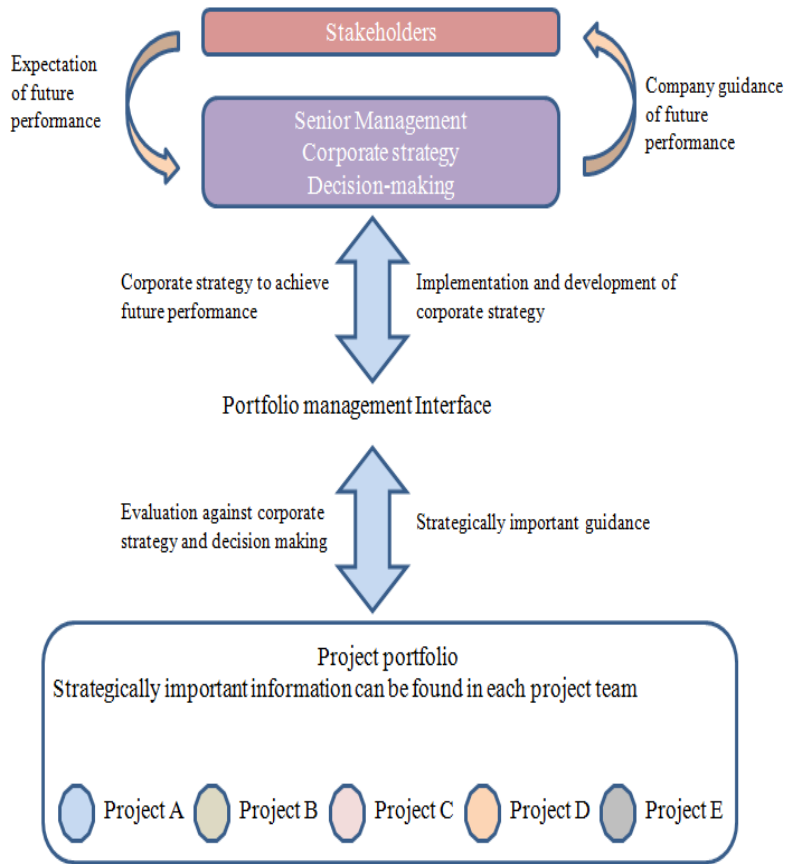

Fig. 2. Project Portfolio management interface with corporate strategy $(* * *, 2011)$

PMO with Process manger will prepared next steps:

- Transferring ARIS data to MS project for construction \& engineering processes and IT processes,
- Developing standard project plans (templates) for all portfolios, and programs

- Developing project plans based on templates for all corporative departments and our representative's offices

Project team will be made of: Process manager, line manager, HR manager, IT manager and PMO manager. Changing "BPM" (Business Process Modeler) and integration of applications is a possible solution to the problem (ARIS, MS Project, BPM, etc.) Business Process Management today calls for software tools that go beyond mere business process modeling and design by business users or consultants. Successful contemporary BPM tools require extensions to the business process models, tools that allow IT to use the models to further refine and technically enrich them for execution. (Rad et al., 2002)

\subsection{Personal resume and lessons learned}

PMO manager suggests that business process reengineering is the fundamental re-thinking and re-designing of a business process in order to exceed customer and quality requirements. The holy grail of a project is usually the results - preferably ones that are measurable, quantifiable and politically correct. They are comfortable because they transport responsibility to some-one else. Much can be invested in choosing the right "someone-else" but in the end the responsibility will be passed on. That "someone-else" will in the end be required to deliver the expected results. $(* * *, 2011)$

\subsection{Results of processes documentation}

JGL has implemented IDS Scheer ARIS, software methodology in description and optimization of key business processes with idea to make crucial value chain activities more efficient and effective. Implementation was finished in the year 2006.

Results of process management in ARIS can be used for project management. R\&D (Research and Development) processes are already transferred to MS Project with interface directly from ARIS and project managers first adapt processes of R\&D with coordination by processes manages, and after that making templates for different type of R\&D projects. Process manager is cooperating with PMO (Project Management Office). (***, 2011)

\section{CONCLUSION}

The benefit of a common view of the project management processes lies, on the one hand, in ensuring the uniformity of the project management approach used hand, on the other hand, in considering the relationships between the sub-processes of project management

In that light, JGL is implementing IDS Scheer ARIS, software methodology in description and optimization of key business processes with idea to make crucial value chain activities more efficient and effective. Key performance indexes are measurable in time periods. (Parametr \& David, 2010)

\section{REFERENCES}

Gareis, Roland (2005) Happy Projects!, Wien, Austria Rad, Parviz F. \& Levin, Ginger (2002.), The advanced PMO, Washington,USA

Kerzner, Harold (2001.), A Systems Approach to Planning, Scheduling, and Controlling, Ohio,USA

Parmenter, David ( 2010 ) Key performance indicators, Hoboken,USA

*** (2011) JGL d.d. Rijeka,CROATIA ( internal document ) 